\title{
Two-weeks repeated-dose oral toxicity study of Pediococcus acidilactici J9 in a mice model
}

\author{
Mijung Lee', Jin-Young Chung ${ }^{2}$, Ka Yeun Kim³ ${ }^{3}$ Wooseok $\mathrm{Im}^{1,4^{*}}$ and Manho Kim ${ }^{1,4,5^{*}}$
}

\begin{abstract}
Background: Helicobacter pylori (H. pylori) is an important pathogen that causes chronic gastritis and peptic ulcer, and is related to the development of gastric carcinoma. Several chemicals, including antibiotics, have been used to eradicate H.pylori. However, more studies are yet requred to accomplish a sufficient therapy. Pediococcus acidilactici (P. acidilactici) J9 were studied for inhibition of binding of H.pylori binding to human gastric cell lines. This study was performed in order to investigate the repeated-dose toxicity of $P$. acidilactici $\mathrm{J} 9$ in male and female mice.

Results: C57BL/6 male and female Mus musculus were divided into four groups ( $n=10$ in each group). P. acidilactici 19 was administered daily by oral injection of vehicle control at dosage levels to a low-dose group ( $500 \mathrm{mg} / \mathrm{kg} / \mathrm{day}$ ), middle-dose group (1000 mg/kg/day), and high-dose group (2000 mg/kg/day) for 2 weeks. After 14 days of exposure, the blood biochemistry and hematology were investigated, along with a histopathology exam. There were no bacterial-related deaths or abnormal clinical signs in either gender of mouse. The data was observed during the period in terms of body weight, food intake, and water consumption. Also, no alterations in organ weights upon administration of $P$. acidilactici J9 alone were observed. The adhesion and growth of $H$. pylori were inhibited by a $24 \mathrm{~h}$ treatment of $\mathrm{H}$. pylori and P. acidilactici $\mathrm{J} 9$ on adenocarcinoma gastric (AGS) cells, which are gastric cancer cells. Compared to the control group (AGS cell and H. pylori), the number of H. pylori analyzed by FACS significantly $(p<0.01)$ decreased after incubation of AGS cell with $P$. acidilactici $J 9$ for $24 \mathrm{~h}$.

Conclusions: These results suggest that the oral application of P. acidilactici J9, up to a dosage level of $2000 \mathrm{mg} /$ $\mathrm{kg} /$ day, causes no adverse effects in both male and female mice. P. acidilactici J9 inhibits the adhesion of H.pylori to AGS cancer cells. When used as probiotics, P. acidilactici 19 may help decrease the occurrence of gastritis and reduce the risk of H.pylori infection with promising safety issues.
\end{abstract}

Keywords: Pediococcus acidilactici J9, Repeated two-week oral dose toxicity, Mouse, Helicobacter pylori, AGS cell

\section{Background}

Lactobacillus is a gram-positive microorganism that utilizes carbohydrates as the energy source and produces organic acids like lactic acid and acetic acid as final products. It is used industrially in various fermented products, like fermented vegetables and dairy products,

* Correspondence: imwooseok@gmail.com; kimmanho@snu.ac.kr 'Department of Neurology, Biomedical Research Institute, Seoul National University Hospital, 101 Daehak-ro, Jongno-gu, Seoul 03080, South Korea Full list of author information is available at the end of the article which are broadly involved in the everyday life $[1,2]$. Lactobacillus determines the flavor of fermented foods and the characteristics of fermented products, and it plays a critical role in the food preservation. This occurs by extending its shelf life via production of active antibiotic materials like organic acid and bacteriocin. Moreover, various function in the human body is also reported, such as the suppression of intestinal noxious bacteria, the decrease of blood cholesterol levels, anticancer effect, reinforcement of immune function, etc.

(c) The Author(s). 2020 Open Access This article is licensed under a Creative Commons Attribution 4.0 International License, which permits use, sharing, adaptation, distribution and reproduction in any medium or format, as long as you give appropriate credit to the original author(s) and the source, provide a link to the Creative Commons licence, and indicate if changes were made. The images or other third party material in this article are included in the article's Creative Commons licence, unless indicated otherwise in a credit line to the material. If material is not included in the article's Creative Commons licence and your intended use is not permitted by statutory regulation or exceeds the permitted use, you will need to obtain permission directly from the copyright holder. To view a copy of this licence, visit http://creativecommons.org/licenses/by/4.0/ The Creative Commons Public Domain Dedication waiver (http://creativecommons.org/publicdomain/zero/1.0/) applies to the data made available in this article, unless otherwise stated in a credit line to the data. 
Because of the Lactobacillus, as a probiotics, intakes living strain, it attracts attention as an antibacterial preparation that solves the residual tolerance problems, in addition to being recently utilized as a healthy functional food $[3,4]$.

Helicobacter pylori is a macroaerophilic gram-negative bacteria that causes chronic gastritis, peptic ulcer, and presumable gastric cancer. Accumulated evidence demonstrates that the eradication of these bacteria resolves H.pylori-associated disease [5]. Multicenter studies have shown that triple therapy via a proton pump inhibitor (PPI), clarithromycin, and either amoxicillin or metronidazole (all taken twice daily). This therapy is among the most effective approaches to $H$. pylori eradication [6]. However, $5-10 \%$ of $H$. pylori strains are reportedly resistant to clarithromycin [7]. In addition, there was a study noted a clarithromycin-resistant mutation in 63\% of $H$. pylori strains from patients in whom treatment with a regimen including clarithromycin was unsuccessful [8]. The treatment of $H$. pylori infection with antibiotics does not eradicate the organism and is also often accompanied by deleterious side effects [9]. Thus, although many experts believe that "untreatable" H. pylori is just ill-treated H. pylori, no clinical trial. To the best of our knowledge, $H$. pylori has not yielded a treatment that provides $100 \%$ eradication [10].

Recently, probiotic lactic acid bacteria (LAB) have been reported to control H. pylori. Also, several studies have examined the efficacy of various probiotic preparations for $H$. pylori eradication with and without cointerventions [11]. Moreover, a number of clinical trials have been undertaken to test the hypothesis that probiotic bacteria inhibits $H$. pylori infection [12]. Probiotics inhibit enteric pathogens such as Salmonella, Shigella, and Citrobacter rodentium in both in vitro and in vivo $[13,14]$, and potential clinical benefits in preventing or resolving gastrointestinal diseases have been demonstrated $[15,16]$. These microorganisms provide gut protection through several mechanisms, including decreasing luminal $\mathrm{pH}$ by producing lactic acid $[17,18]$ and competing with gut pathogens for host surface receptors [19]. Nonetheless, it has been shown that probiotics may inhibit $H$. pylori growth, independent of $\mathrm{pH}$ and lactic acid levels [20].

We have focused on $P$. acidilactici J9, originated from Kimchi and Cheonguk-jang [21], which produces bacteriocin [22] that is known as a considerably widely used antibacterial agent. Recently, $P$. acidilactici $\mathrm{J} 9$ is attracting attention as probiotics because it has interesting properties, such as resistance to heat, cold, $\mathrm{pH}$, and proteolytic treatments, which are the required properties for probiotics [23]. It is reported that $P$. acidilactici has the ability to survive through gastrointestinal tract passage, can survive from a drying process and during storage at $4^{\circ} \mathrm{C}$ for 60 days [24]. Moreover, P. acidilactici has been reported to have in vitro acvitity against $H$. pylori [25].
However, a systematic study on its repeated oral administration toxicity has not been reported yet. Therefore, we have investigated the toxicity of this new probiotics and its effect on the inhibition of growth of H. pylori. In vitro assays were carried out to determine whether the combination of $P$. acidilactici $\mathrm{J} 9$, and its adhesion to gastric cells thus impacting gastric acidity, inhibit the growth of $H$. pylori [26]. The current therapeutic regimen for $H$. pylori aims to eliminate bacterial growth with antibiotics and this reduces the total acidity of gastric acid.

In this study, repeated toxicity tests are performed as the stability test using mice of C57BL/6 type under the "standard of toxicity test for medicine and medical supplies (Korea food and drug administration notification No. 1999-61)". We also demonstrated in in vitro models that $P$. acidilactici $\mathrm{J9}$ in combination have beneficial effects similar to those of antibiotic therapy on H. pyloriinfected gastric epithelium.

\section{Results}

Oral toxicity study of $P$. acidilactici $\mathrm{J9}$ in a mice model: death rate and normal symptoms

$P$. acidilactici $\mathrm{J} 9$ was administrated by oral injection for 2 weeks and the Table 1 show the death rate and the normal symptoms of males and females observed for 2 weeks. During the experiment, experimental mice were observed at regular times, and no death was observed in the male and female administration group (Table 1). Also, during all of the experiment, in every administration group - low dose $(500 \mathrm{mg} / \mathrm{kg} /$ day $)$, medium dose $(1000 \mathrm{mg} / \mathrm{kg} /$ day $)$, and high dose $(2000 \mathrm{mg} / \mathrm{kg} /$ day $)$ - including the control group, no specific adverse symptoms are observed. In this study, a dose of $2000 \mathrm{mg} / \mathrm{kg}$, which is a maximum dose of oral administration toxicity test, did not generate abnormal symptoms. It thus seems that

Table 1 Mortality and clinical signs of male and female (mice) treated orally with $P$. acidilactici J9 for 14 days

\begin{tabular}{|c|c|c|c|c|c|c|c|c|}
\hline \multirow[t]{2}{*}{ Sex } & \multirow{2}{*}{$\begin{array}{l}\text { Dose } \\
\text { (mg) }\end{array}$} & \multirow{2}{*}{$\begin{array}{l}\text { No. of } \\
\text { animal }\end{array}$} & \multicolumn{4}{|c|}{ Days after treatment } & \multirow{2}{*}{$\begin{array}{l}\text { Final } \\
\text { mortality }\end{array}$} & \multirow{2}{*}{$\begin{array}{l}\text { Clinical } \\
\text { signs }\end{array}$} \\
\hline & & & 0 & 7 & 14 & End & & \\
\hline \multirow[t]{4}{*}{ Male } & Control & 5 & $0 / 5$ & $0 / 5$ & $0 / 5$ & T.S & $0 / 5$ & NAD \\
\hline & 500 & 5 & $0 / 5$ & $0 / 5$ & $0 / 5$ & T.S & $0 / 5$ & NAD \\
\hline & 1000 & 5 & $0 / 5$ & $0 / 5$ & $0 / 5$ & T.S & $0 / 5$ & NAD \\
\hline & 2000 & 5 & $0 / 5$ & $0 / 5$ & $0 / 5$ & T.S & $0 / 5$ & NAD \\
\hline \multirow[t]{4}{*}{ Female } & Control & 5 & $0 / 5$ & $0 / 5$ & $0 / 5$ & T.S & $0 / 5$ & NAD \\
\hline & 500 & 5 & $0 / 5$ & $0 / 5$ & $0 / 5$ & T.S & $0 / 5$ & NAD \\
\hline & 1000 & 5 & $0 / 5$ & $0 / 5$ & $0 / 5$ & T.S & $0 / 5$ & NAD \\
\hline & 2000 & 5 & $0 / 5$ & $0 / 5$ & $0 / 5$ & T.S & $0 / 5$ & NAD \\
\hline
\end{tabular}

Values are expressed as the numbers of dead animals/total numbers of animals

Values are expressed as number of animals with the sign/number of animals examined

T.S terminal sacrifice, NAD no abnormalities detected 
the minimal lethal dose of this experimental materials exceeds $2000 \mathrm{mg} / \mathrm{kg} /$ day in both male and female.

\section{Oral toxicity study of $P$. acidilactici J9 in a mice model: changes in body weight}

P. acidilactici $\mathrm{J} 9$ was orally administrated for 2 weeks with varying concentrations and the changes in body weight are shown in Table 2. Changes in body weight during the whole period of experiment were negligible for the control group, low dose group $(500 \mathrm{mg} / \mathrm{kg} /$ day), medium dose group $(1000 \mathrm{mg} / \mathrm{kg} /$ day $)$, and high dose group $(2000 \mathrm{mg} / \mathrm{kg} /$ day). Additionally, from the date of administration of experimental materials to the end of the experiment, there was a normal weekly increase in body weight in the control group and the administration group (Fig. 1a).

\section{Oral toxicity study of $P$. acidilactici $\mathrm{J9}$ in a mice model: intake of nutrition and water}

There was no significant change in the control group and the experimental material administration group in the amount of intake of feed and water during the experiment period (Table 3). Although the water consumption was significantly reduced on day 14 when compared to day 7 , since it was both seen in the control group and the administration group, so it could be regarded as the environmental effect, not an effect of administration. Therefore, it seems that the administration of experimental materials does not affect significantly the amount of intake of feed and water (Fig. 1b and c).

\section{Oral toxicity study of $P$. acidilactici J9 in a mice model: necropsy results}

As the result of the observation of main organs with naked eyes after the necropsy of experimental mice, there was no significant change in organs and specific necropsy opinion dependent on the dose of administration (Table 4). Some

Table 2 Body weight changes of male and female (mice) treated orally with $P$. acidilactici 19 for 14 days

\begin{tabular}{lllll}
\hline Sex & $\begin{array}{l}\text { Dose } \\
(\mathbf{m g})\end{array}$ & \multicolumn{3}{l}{$\begin{array}{l}\text { Body weight } \mathbf{( g )} \\
\text { Days after treatment }\end{array}$} \\
\cline { 3 - 5 } & & $\mathbf{0}$ & $\mathbf{7}$ & $\mathbf{1 4}$ \\
\hline Male & Control & $19.07 \pm 0.80^{\mathrm{NS}}$ & $19.64 \pm 0.95^{\mathrm{NS}}$ & $20.62 \pm 1.13^{\mathrm{NS}}$ \\
& 500 & $18.79 \pm 1.32$ & $19.40 \pm 1.53$ & $20.22 \pm 1.39$ \\
& 1000 & $19.21 \pm 0.70$ & $19.90 \pm 1.04$ & $20.59 \pm 1.11$ \\
& 2000 & $19.08 \pm 0.92$ & $19.89 \pm 1.50$ & $20.83 \pm 1.79$ \\
Female & Control & $16.60 \pm 0.96^{\mathrm{NS}}$ & $16.67 \pm 0.77^{\mathrm{NS}}$ & $17.79 \pm 0.77^{\mathrm{NS}}$ \\
& 500 & $16.64 \pm 0.64$ & $16.94 \pm 0.40$ & $17.49 \pm 0.47$ \\
& 1000 & $16.41 \pm 0.64$ & $16.78 \pm 0.71$ & $17.37 \pm 0.79$ \\
& 2000 & $16.30 \pm 0.79$ & $16.16 \pm 0.96$ & $16.92 \pm 0.85$ \\
\hline
\end{tabular}

Values are expressed as mean $\pm \mathrm{SE}(n=5)$

NS not significantly different among groups mice from female control group were excluded from the data due to black damaged areas of the spleen during organ harvest, which is just the characteristics of a mouse individual. However in both control group and administration group, blackish red discoloration at the spleen terminal, shrinkage of the right testicle, and thinning of the right atrium were observed. (CTR-F-001: discoloration of spleen; CTR-F-005: discoloration of spleen; 500 mg-F-001: discoloration of spleen; CTR-M-004: discoloration of spleen; CTR-M-005: thinning of right atrium; $500 \mathrm{mg}-\mathrm{M}-$ 004: discoloration of spleen; $1000 \mathrm{mg}-\mathrm{M}-004$ : shrinkage of right testicle) However, as the same phenomenon was seen in the control group and the administration group, these are the characteristics of a mouse individual and is not an effect of administration.

\section{Oral toxicity study of $P$. acidilactici $\mathrm{J} 9$ in a mice model: the weight of organs}

The weight of organs were measured after repeated administration of $P$. acidilactici $\mathrm{J} 9$ which varied to low dose $(500 \mathrm{mg} / \mathrm{kg} /$ day $)$, medium dose $(1000 \mathrm{mg} / \mathrm{kg} /$ day $)$, and high dose $(2000 \mathrm{mg} / \mathrm{kg} /$ day) for 2 weeks (Table 5). No changes were observed in the weight of brain, lung, testis, ovary, kidney, heart, spleen, and liver with respect to the administration of experimental materials and no abnormal changes were dependent on dose of administrations. Generally, when the toxic materials were ingested, liver takes the largest effect since the detoxification starts at the liver. However, there were no significant changes in each group on the observed weight of the liver. From the results above, the administration of $P$. acidilactici J9 does not affect the weight of organs.

\section{Oral toxicity study of $P$. acidilactici $\mathrm{J9}$ in a mice model: hematological tests}

As the result of the measurement of hematological parameters, no significant changes were observed in control and administration groups $(p \leq 0.05)$ (Table 6). As a result of hematological examination, both the control group and the administration group were included in normal range and no dependence on dose was observed. This result is similar to the range previously reported in hematological fundamental database of which there is a repeated toxicity test for 2 weeks using mice.

\section{Oral toxicity study of $P$. acidilactici J9 in a mice model: blood biochemical analysis}

As the result of the measurement of the indicator of blood biochemistry, no significant changes dependent on the administration of experimental materials were observed in the whole administration groups with respect to the control group. Both the control group and $P$. acidilactici $\mathrm{J} 9$ administration group showed normal parameters $(p \leq 0.05)$ (Table 7$)$. 


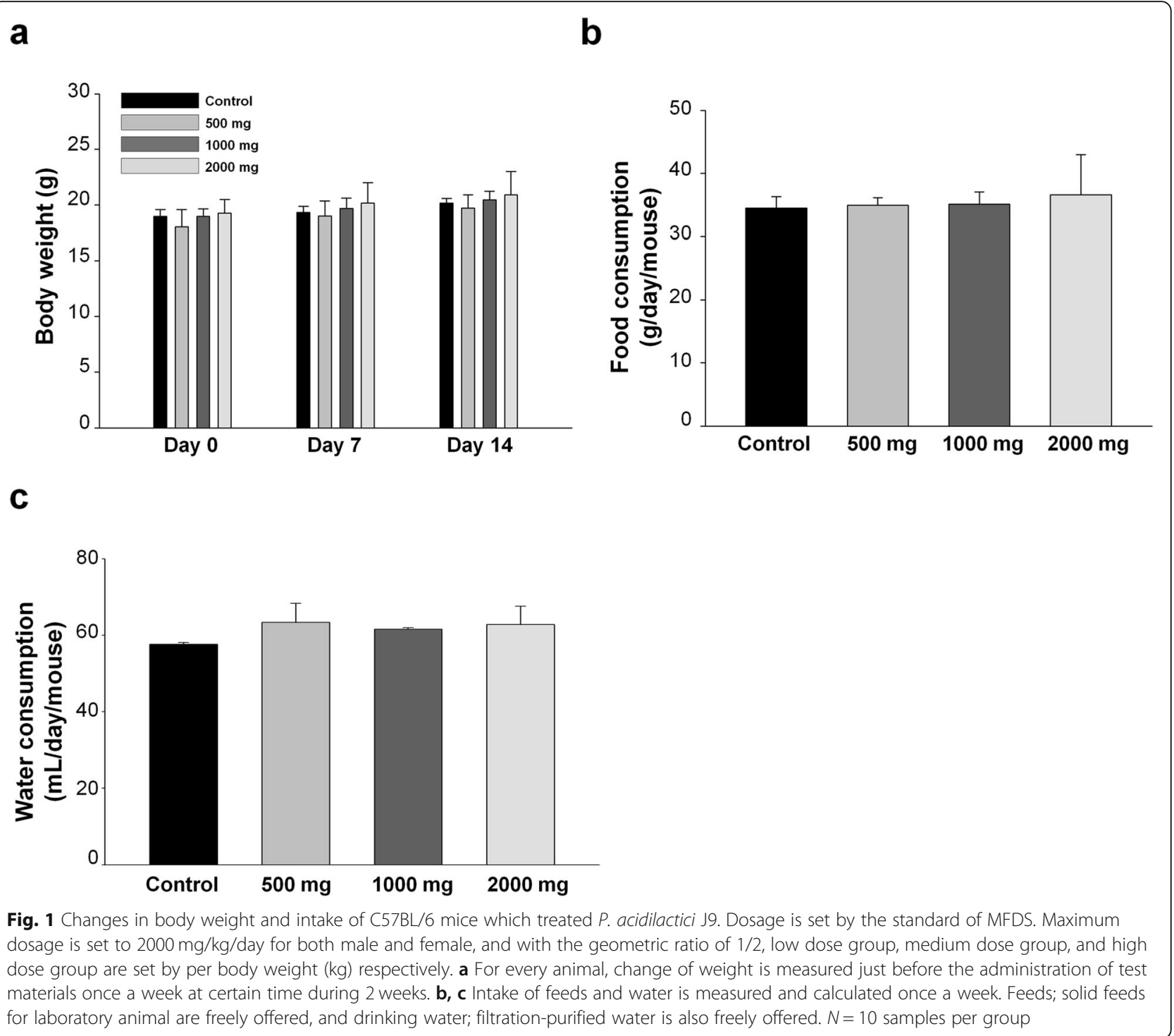

Table 3 Daily food and water consumption of male and female (mice) treated orally with P. acidilactici J9 for 14 days

\begin{tabular}{|c|c|c|c|c|c|}
\hline \multirow[t]{2}{*}{ Sex } & \multirow[t]{2}{*}{ Dose (mg) } & \multicolumn{2}{|c|}{$\begin{array}{l}\text { Food consumption ( } g / \text { day/mouse) } \\
\text { Days after treatment }\end{array}$} & \multicolumn{2}{|c|}{$\begin{array}{l}\text { Water consumption (mL/day/mouse) } \\
\text { Days after treatment }\end{array}$} \\
\hline & & 7 & 14 & 7 & 14 \\
\hline \multirow[t]{4}{*}{ Male } & Control & $74^{\mathrm{NS}}$ & $87^{\mathrm{NS}}$ & $139^{\mathrm{NS}}$ & $120^{\mathrm{NS}}$ \\
\hline & 500 & 92 & 91 & 141 & 118 \\
\hline & 1000 & 71 & 95 & 137 & 111 \\
\hline & 2000 & 113 & 93 & 154 & 137 \\
\hline \multirow[t]{4}{*}{ Female } & Control & $103^{N S}$ & $83^{\mathrm{NS}}$ & $127^{\mathrm{NS}}$ & $124^{\mathrm{NS}}$ \\
\hline & 500 & 85 & 81 & 148 & 129 \\
\hline & 1000 & 108 & 79 & 142 & 152 \\
\hline & 2000 & 65 & 70 & 132 & 112 \\
\hline
\end{tabular}

Values are expressed as mean $(n=5)$

NS not significantly different among groups 
Table 4 Gross findings of male and female (mice) treated orally with P. acidilactici J9 for 14 days

\begin{tabular}{|c|c|c|c|c|c|c|c|c|c|}
\hline \multirow{2}{*}{$\begin{array}{l}\text { Sex } \\
\text { Dose (mg) }\end{array}$} & & \multicolumn{4}{|l|}{ Male } & \multicolumn{4}{|l|}{ Female } \\
\hline & & Control & 500 & 1000 & 2000 & Control & 500 & 1000 & 2000 \\
\hline Brain & NGF & $5(100)$ & $5(100)$ & $5(100)$ & $5(100)$ & $5(100)$ & $5(100)$ & $5(100)$ & $5(100)$ \\
\hline Lung & NGF & $5(100)$ & $5(100)$ & $5(100)$ & $5(100)$ & $5(100)$ & $5(100)$ & $5(100)$ & $5(100)$ \\
\hline Liver & NGF & $5(100)$ & $5(100)$ & $5(100)$ & $5(100)$ & $5(100)$ & $5(100)$ & $5(100)$ & $5(100)$ \\
\hline Heart & NGF & $4(90)$ & $5(100)$ & $5(100)$ & $5(100)$ & $5(100)$ & $5(100)$ & $5(100)$ & $5(100)$ \\
\hline Kidney(L) & NGF & $5(100)$ & $5(100)$ & $5(100)$ & $5(100)$ & $5(100)$ & $5(100)$ & $5(100)$ & $5(100)$ \\
\hline Kidney(R) & NGF & $5(100)$ & $5(100)$ & $5(100)$ & $5(100)$ & $5(100)$ & $5(100)$ & $5(100)$ & $5(100)$ \\
\hline Testis(L) & NGF & $5(100)$ & $5(100)$ & $5(100)$ & $5(100)$ & & & & \\
\hline Testis(R) & NGF & $5(100)$ & $5(100)$ & $4(90)$ & $5(100)$ & & & & \\
\hline Ovary(L) & NGF & & & & & $5(100)$ & $5(100)$ & $5(100)$ & $5(100)$ \\
\hline Ovary(R) & NGF & & & & & $5(100)$ & $5(100)$ & $5(100)$ & $5(100)$ \\
\hline Spleen & NGF & $4(90)$ & $4(90)$ & $5(100)$ & $5(100)$ & $3(70)$ & $4(90)$ & $5(100)$ & $5(100)$ \\
\hline Thymus & NGF & $5(100)$ & $5(100)$ & $5(100)$ & $5(100)$ & $5(100)$ & $5(100)$ & $5(100)$ & $5(100)$ \\
\hline
\end{tabular}

Values are expressed as animal numbers (the percentage of animal numbers)

$N G F$ no gross finding

Table 5 Organ weights of male and female (mice) treated orally with P. acidilactici J9 for 14 days

\begin{tabular}{|c|c|c|c|c|c|}
\hline \multirow{3}{*}{ Sex } & \multirow{3}{*}{ Organs } & \multicolumn{4}{|l|}{ (Unit: g) } \\
\hline & & \multicolumn{4}{|l|}{ Dose (mg) } \\
\hline & & Control & 500 & 1000 & 2000 \\
\hline \multirow[t]{10}{*}{ Male } & Brain & $0.445 \pm 0.014$ & $0.440 \pm 0.014$ & $0.444 \pm 0.015$ & $0.437 \pm 0.016$ \\
\hline & Lung & $0.124 \pm 0.013$ & $0.126 \pm 0.006$ & $0.125 \pm 0.010$ & $0.134 \pm 0.023$ \\
\hline & Liver & $0.984 \pm 0.208$ & $0.920 \pm 0.065$ & $0.929 \pm 0.183$ & $0.904 \pm 0.176$ \\
\hline & Heart & $0.104 \pm 0.011$ & $0.101 \pm 0.007$ & $0.100 \pm 0.008$ & $0.105 \pm 0.010$ \\
\hline & Kidney(L) & $0.129 \pm 0.025$ & $0.128 \pm 0.025$ & $0.127 \pm 0.13$ & $0.126 \pm 0.018$ \\
\hline & Kidney(R) & $0.133 \pm 0.025$ & $0.136 \pm 0.011$ & $0.134 \pm 0.017$ & $0.140 \pm 0.029$ \\
\hline & Testis $(L)$ & $0.071 \pm 0.020$ & $0.067 \pm 0.000$ & $0.067 \pm 0.008$ & $0.071 \pm 0.006$ \\
\hline & Testis(R) & $0.074 \pm 0.024$ & $0.070 \pm 0.000$ & $0.063 \pm 0.018$ & $0.074 \pm 0.007$ \\
\hline & Spleen & $0.057 \pm 0.009$ & $0.052 \pm 0.007$ & $0.050 \pm 0.006$ & $0.054 \pm 0.014$ \\
\hline & Thymus & $0.042 \pm 0.010$ & $0.046 \pm 0.007$ & $0.044 \pm 0.007$ & $0.045 \pm 0.008$ \\
\hline \multirow[t]{10}{*}{ Female } & Brain & $0.443 \pm 0.014$ & $0.434 \pm 0.019$ & $0.437 \pm 0.013$ & $0.431 \pm 0.018$ \\
\hline & Lung & $0.120 \pm 0.006$ & $0.120 \pm 0.008$ & $0.134 \pm 0.014$ & $0.121 \pm 0.017$ \\
\hline & Liver & $0.775 \pm 0.065$ & $0.788 \pm 0.199$ & $0.755 \pm 0.092$ & $0.727 \pm 0.103$ \\
\hline & Heart & $0.091 \pm 0.007$ & $0.089 \pm 0.005$ & $0.105 \pm 0.007$ & $0.084 \pm 0.007$ \\
\hline & Kidney(L) & $0.114 \pm 0.025$ & $0.102 \pm 0.011$ & $0.126 \pm 0.007$ & $0.102 \pm 0.010$ \\
\hline & Kidney(R) & $0.110 \pm 0.011$ & $0.110 \pm 0.013$ & $0.140 \pm 0.012$ & $0.105 \pm 0.012$ \\
\hline & Ovary (L) & $0.001 \pm 0.000$ & $0.002 \pm 0.000$ & $0.002 \pm 0.000$ & $0.001 \pm 0.000$ \\
\hline & Ovary(R) & $0.002 \pm 0.000$ & $0.002 \pm 0.000$ & $0.002 \pm 0.000$ & $0.002 \pm 0.000$ \\
\hline & Spleen & $0.058 \pm 0.007$ & $0.052 \pm 0.010$ & $0.053 \pm 0.010$ & $0.051 \pm 0.007$ \\
\hline & Thymus & $0.077 \pm 0.007$ & $0.071 \pm 0.010$ & $0.045 \pm 0.011$ & $0.076 \pm 0.014$ \\
\hline
\end{tabular}


Table 6 Hematology of male and female (mice) treated orally with P. acidilactici J9 for 14 days

\begin{tabular}{|c|c|c|c|c|c|c|}
\hline \multirow[t]{2}{*}{ Sex } & \multirow{2}{*}{\multicolumn{2}{|c|}{ Parameters }} & \multicolumn{4}{|l|}{ Dose (mg) } \\
\hline & & & Control & 500 & 1000 & 2000 \\
\hline \multirow[t]{36}{*}{ Male } & \multirow[t]{16}{*}{ CBC } & WBC $\left(\times 10^{3} / \mu \mathrm{L}\right)$ & $2.672 \pm 0.65$ & $2.066 \pm 0.63$ & $2.016 \pm 1.01$ & $2.474 \pm 0.96$ \\
\hline & & $\mathrm{RBC}\left(\times 10^{6} / \mu \mathrm{L}\right)$ & $9.88 \pm 0.33$ & $9.518 \pm 0.26$ & $10.00 \pm 0.14$ & $9.876 \pm 0.32$ \\
\hline & & $\mathrm{HGB}(\mathrm{g} / \mathrm{dL})$ & $15.14 \pm 0.64$ & $14.72 \pm 0.36$ & $15.36 \pm 0.28$ & $15.26 \pm 0.53$ \\
\hline & & HCT (\%) & $51.62 \pm 2.24$ & $49.42 \pm 1.43$ & $51.38 \pm 1.17$ & $50.90 \pm 2.09$ \\
\hline & & MCV (fL) & $52.26 \pm 0.69$ & $51.9 \pm 0.42$ & $51.36 \pm 1.09$ & $51.54 \pm 0.72$ \\
\hline & & $\mathrm{MCH}(\mathrm{pg})$ & $15.32 \pm 0.22$ & $15.46 \pm 0.21$ & $15.34 \pm 0.22$ & $15.46 \pm 0.23$ \\
\hline & & $\mathrm{MCHC}(\mathrm{g} / \mathrm{dL})$ & $29.30 \pm 0.23$ & $29.78 \pm 0.29$ & $29.88 \pm 0.43$ & $29.96 \pm 0.40$ \\
\hline & & CHCM (g/dL) & $28.16 \pm 0.35$ & $28.16 \pm 0.11$ & $28.64 \pm 0.44$ & $28.68 \pm 0.45$ \\
\hline & & RDW (\%) & $13.36 \pm 0.38$ & $13.88 \pm 0.40$ & $13.30 \pm 0.50$ & $13.26 \pm 0.94$ \\
\hline & & HDW (g/dL) & $1.45 \pm 0.02$ & $1.45 \pm 0.06$ & $1.45 \pm 0.04$ & $1.45 \pm 0.03$ \\
\hline & & $\mathrm{CH}(\mathrm{pg})$ & $14.68 \pm 0.19$ & $14.58 \pm 0.08$ & $14.66 \pm 0.17$ & $14.74 \pm 0.09$ \\
\hline & & CHDW (\%) & $2.00 \pm 0.05$ & $2.07 \pm 0.08$ & $2.00 \pm 0.05$ & $2.01 \pm 0.11$ \\
\hline & & $\operatorname{PLT}\left(\times 10^{3} / \mu \mathrm{L}\right)$ & $1263.20 \pm 73.52$ & $1244.80 \pm 57.87$ & $1238.60 \pm 61.75$ & $1202.00 \pm 60.76$ \\
\hline & & MPV (fL) & $7.44 \pm 0.17$ & $7.88 \pm 0.05$ & $7.52 \pm 0.08$ & $7.48 \pm 0.26$ \\
\hline & & PDW (\%) & $60.38 \pm 1.85$ & $57.30 \pm 1.62$ & $55.80 \pm 1.62$ & $55.96 \pm 2.34$ \\
\hline & & PCT (\%) & $0.94 \pm 0.06$ & $0.98 \pm 0.05$ & $0.93 \pm 0.05$ & $0.90 \pm 0.06$ \\
\hline & \multirow[t]{12}{*}{ DIFF } & $\operatorname{NEUT}\left(\times 10^{3} / \mu \mathrm{L}\right)$ & $0.34 \pm 0.13$ & $0.18 \pm 0.05$ & $0.19 \pm 0.09$ & $0.21 \pm 0.05$ \\
\hline & & NEUT (\%) & $12.5 \pm 3.19$ & $9.26 \pm 2.15$ & $9.56 \pm 1.06$ & $8.94 \pm 1.50$ \\
\hline & & LYMPH $\left(\times 10^{3} / \mu \mathrm{L}\right)$ & $2.25 \pm 0.52$ & $1.83 \pm 0.56$ & $1.78 \pm 0.89$ & $2.22 \pm 0.89$ \\
\hline & & LYMPH (\%) & $84.46 \pm 3.46$ & $88.48 \pm 2.27$ & $88.52 \pm 1.21$ & $89.46 \pm 1.17$ \\
\hline & & MONO $\left(\times 10^{3} / \mu \mathrm{L}\right)$ & $0.02 \pm 0.01$ & $0.01 \pm 0.01$ & $0.01 \pm 0.01$ & $0.01 \pm 0.01$ \\
\hline & & MONO (\%) & $0.54 \pm 0.34$ & $0.32 \pm 0.28$ & $0.28 \pm 0.18$ & $0.32 \pm 0.16$ \\
\hline & & $\operatorname{EOS}\left(\times 10^{3} / \mu \mathrm{L}\right)$ & $0.05 \pm 0.02$ & $0.03 \pm 0.04$ & $0.02 \pm 0.01$ & $0.01 \pm 0.01$ \\
\hline & & EOS (\%) & $1.64 \pm 0.50$ & $1.30 \pm 1.31$ & $0.76 \pm 0.30$ & $0.48 \pm 0.21$ \\
\hline & & BASO $\left(\times 10^{3} / \mu \mathrm{L}\right)$ & $0.01 \pm 0.01$ & $0.01 \pm 0.01$ & $0.01 \pm 0.01$ & $0.01 \pm 0.01$ \\
\hline & & BASO (\%) & $0.28 \pm 0.13$ & $0.40 \pm 0.20$ & $0.34 \pm 0.24$ & $0.26 \pm 0.19$ \\
\hline & & LUC $\left(\times 10^{3} / \mu \mathrm{L}\right)$ & $0.02 \pm 0.01$ & $0.01 \pm 0.01$ & $0.01 \pm 0.01$ & $0.02 \pm 0.01$ \\
\hline & & LUC (\%) & $0.62 \pm 0.16$ & $0.24 \pm 0.27$ & $0.48 \pm 0.33$ & $0.56 \pm 0.23$ \\
\hline & \multirow[t]{8}{*}{ RETI } & Reticulocyte $\left(\times 10^{9} / \mu \mathrm{L}\right)$ & $301.60 \pm 47.96$ & $258.32 \pm 30.72$ & $302.89 \pm 10.26$ & $298.02 \pm 63.69$ \\
\hline & & Reticulocyte (\%) & $3.15 \pm 0.51$ & $2.71 \pm 0.25$ & $3.03 \pm 0.12$ & $3.00 \pm 0.56$ \\
\hline & & $\mathrm{MCVr}(\mathrm{fL})$ & $58.00 \pm 0.51$ & $57.46 \pm 0.48$ & $57.60 \pm 0.65$ & $57.86 \pm 1.13$ \\
\hline & & CHCMr (g/dL) & $26.24 \pm 0.17$ & $25.92 \pm 0.13$ & $26.30 \pm 0.19$ & $26.18 \pm 0.31$ \\
\hline & & RDWr (\%) & $12.06 \pm 0.65$ & $12.36 \pm 0.66$ & $11.96 \pm 0.64$ & $12.20 \pm 0.85$ \\
\hline & & HDWr (\%) & $2.34 \pm 0.12$ & $2.40 \pm 0.10$ & $2.43 \pm 0.07$ & $2.52 \pm 0.10$ \\
\hline & & $\mathrm{CHr}(\mathrm{pg})$ & $15.20 \pm 0.25$ & $14.86 \pm 0.22$ & $15.12 \pm 0.11$ & $15.12 \pm 0.16$ \\
\hline & & CHDWr (\%) & $1.98 \pm 0.08$ & $1.97 \pm 0.07$ & $1.92 \pm 0.05$ & $1.97 \pm 0.06$ \\
\hline \multirow[t]{7}{*}{ Female } & \multirow[t]{7}{*}{$\mathrm{CBC}$} & WBC $\left(\times 10^{3} / \mu \mathrm{L}\right)$ & $2.95 \pm 0.60$ & $2.53 \pm 1.08$ & $2.75 \pm 0.70$ & $3.32 \pm 1.34$ \\
\hline & & $\mathrm{RBC}\left(\times 10^{6} / \mu \mathrm{L}\right)$ & $9.51 \pm 0.13$ & $10.19 \pm 0.15$ & $10.07 \pm 0.22$ & $9.97 \pm 0.31$ \\
\hline & & $\mathrm{HGB}(\mathrm{g} / \mathrm{dL})$ & $14.72 \pm 0.21$ & $15.80 \pm 0.47$ & $15.60 \pm 0.26$ & $15.74 \pm 0.31$ \\
\hline & & $\mathrm{HCT}(\%)$ & $49.12 \pm 0.73$ & $52.20 \pm 1.70$ & $51.48 \pm 1.52$ & $50.44 \pm 1.77$ \\
\hline & & $\mathrm{MCV}(\mathrm{fL})$ & $51.64 \pm 0.43$ & $51.16 \pm 1.04$ & $51.12 \pm 0.79$ & $50.60 \pm 0.62$ \\
\hline & & $\mathrm{MCH}(\mathrm{pg})$ & $15.50 \pm 0.23$ & $15.48 \pm 0.33$ & $15.50 \pm 0.33$ & $15.78 \pm 0.42$ \\
\hline & & $\mathrm{MCHC}(\mathrm{g} / \mathrm{dL})$ & $29.98 \pm 0.36$ & $30.28 \pm 0.35$ & $30.32 \pm 0.61$ & $31.20 \pm 0.91$ \\
\hline
\end{tabular}


Table 6 Hematology of male and female (mice) treated orally with P. acidilactici 19 for 14 days (Continued)

\begin{tabular}{|c|c|c|c|c|c|c|}
\hline \multirow[t]{2}{*}{ Sex } & \multirow{2}{*}{\multicolumn{2}{|c|}{ Parameters }} & \multicolumn{4}{|l|}{ Dose (mg) } \\
\hline & & & \multirow{2}{*}{$\begin{array}{l}\text { Control } \\
28.74 \pm 0.34\end{array}$} & \multirow{2}{*}{$\begin{array}{l}\mathbf{5 0 0} \\
28.94 \pm 0.40\end{array}$} & \multirow{2}{*}{$\begin{array}{l}1000 \\
28.96 \pm 0.43\end{array}$} & \multirow{2}{*}{$\begin{array}{l}2000 \\
29.5 \pm 0.35\end{array}$} \\
\hline & & CHCM (g/dL) & & & & \\
\hline & & RDW (\%) & $13.68 \pm 0.46$ & $13.90 \pm 0.46$ & $13.00 \pm 0.52$ & $13.02 \pm 0.46$ \\
\hline & & HDW (g/dL) & $1.50 \pm 0.05$ & $1.54 \pm 0.03$ & $1.52 \pm 0.04$ & $1.59 \pm 0.02$ \\
\hline & & $\mathrm{CH}(\mathrm{pg})$ & $14.76 \pm 0.13$ & $14.74 \pm 0.21$ & $14.76 \pm 0.15$ & $14.86 \pm 0.06$ \\
\hline & & CHDW (\%) & $2.07 \pm 0.06$ & $2.11 \pm 0.05$ & $2.00 \pm 0.08$ & $2.03 \pm 0.06$ \\
\hline & & $\mathrm{PLT}\left(\times 10^{3} / \mu \mathrm{L}\right)$ & $955.60 \pm 64.27$ & $1102.40 \pm 63.27$ & $1129.80 \pm 94.82$ & $1035.00 \pm 107.62$ \\
\hline & & MPV (fL) & $7.56 \pm 0.35$ & $7.70 \pm 0.16$ & $7.82 \pm 0.11$ & $7.38 \pm 0.47$ \\
\hline & & PDW (\%) & $57.78 \pm 3.04$ & $57.10 \pm 2.82$ & $54.94 \pm 1.31$ & $57.68 \pm 3.19$ \\
\hline & & PCT (\%) & $0.73 \pm 0.07$ & $0.85 \pm 0.06$ & $0.89 \pm 0.08$ & $0.77 \pm 0.11$ \\
\hline & \multirow[t]{12}{*}{ DIFF } & NEUT $\left(\times 10^{3} / \mu \mathrm{L}\right)$ & $0.28 \pm 0.07$ & $0.29 \pm 0.06$ & $0.25 \pm 0.08$ & $0.23 \pm 0.12$ \\
\hline & & NEUT (\%) & $9.48 \pm 0.42$ & $12.38 \pm 2.50$ & $9.70 \pm 3.01$ & $6.94 \pm 1.34$ \\
\hline & & LYMPH $\left(\times 10^{3} / \mu \mathrm{L}\right)$ & $2.61 \pm 0.53$ & $2.20 \pm 1.01$ & $2.45 \pm 0.72$ & $3.03 \pm 1.19$ \\
\hline & & LYMPH (\%) & $88.50 \pm 0.39$ & $86.24 \pm 2.40$ & $88.74 \pm 3.30$ & $91.42 \pm 1.61$ \\
\hline & & MONO $\left(\times 10^{3} / \mu \mathrm{L}\right)$ & $0.01 \pm 0.00$ & $0.00 \pm 0.01$ & $0.01 \pm 0.01$ & $0.01 \pm 0.00$ \\
\hline & & MONO (\%) & $0.46 \pm 0.15$ & $0.20 \pm 0.12$ & $0.22 \pm 0.13$ & $0.22 \pm 0.08$ \\
\hline & & $\operatorname{EOS}\left(\times 10^{3} / \mu \mathrm{L}\right)$ & $0.02 \pm 0.01$ & $0.01 \pm 0.01$ & $0.01 \pm 0.01$ & $0.01 \pm 0.01$ \\
\hline & & EOS (\%) & $0.80 \pm 0.25$ & $0.34 \pm 0.38$ & $0.34 \pm 0.26$ & $0.42 \pm 0.29$ \\
\hline & & $\operatorname{BASO}\left(\times 10^{3} / \mu \mathrm{L}\right)$ & $0.01 \pm 0.01$ & $0.01 \pm 0.01$ & $0.01 \pm 0.00$ & $0.01 \pm 0.01$ \\
\hline & & BASO (\%) & $0.32 \pm 0.22$ & $0.30 \pm 0.12$ & $0.38 \pm 0.19$ & $0.30 \pm 0.19$ \\
\hline & & $\operatorname{LUC}\left(\times 10^{3} / \mu \mathrm{L}\right)$ & $0.01 \pm 0.01$ & $0.02 \pm 0.01$ & $0.02 \pm 0.01$ & $0.03 \pm 0.02$ \\
\hline & & LUC (\%) & $0.48 \pm 0.13$ & $0.54 \pm 0.18$ & $0.64 \pm 0.51$ & $0.66 \pm 0.38$ \\
\hline & \multirow[t]{8}{*}{ RETI } & Reticulocyte $\left(\times 10^{9} / \mu \mathrm{L}\right)$ & $309.34 \pm 52.93$ & $304.60 \pm 43.32$ & $277.50 \pm 38.28$ & $351.10 \pm 49.29$ \\
\hline & & Reticulocyte (\%) & $3.25 \pm 0.53$ & $2.99 \pm 0.42$ & $2.76 \pm 0.41$ & $3.53 \pm 0.60$ \\
\hline & & $M C V r(f L)$ & $57.90 \pm 0.50$ & $57.86 \pm 1.25$ & $57.36 \pm 0.70$ & $58.12 \pm 0.75$ \\
\hline & & CHCMr (g/dL) & $26.46 \pm 0.18$ & $26.42 \pm 0.33$ & $26.44 \pm 0.11$ & $26.76 \pm 0.23$ \\
\hline & & RDWr (\%) & $13.08 \pm 0.93$ & $12.14 \pm 1.01$ & $13.40 \pm 0.70$ & $13.22 \pm 1.00$ \\
\hline & & HDWr (\%) & $2.58 \pm 0.11$ & $2.63 \pm 0.11$ & $2.75 \pm 0.12$ & $2.81 \pm 0.12$ \\
\hline & & $\mathrm{CHr}(\mathrm{pg})$ & $15.30 \pm 0.23$ & $15.24 \pm 0.42$ & $15.12 \pm 0.22$ & $15.52 \pm 0.13$ \\
\hline & & CHDWr (\%) & $2.03 \pm 0.04$ & $2.01 \pm 0.08$ & $2.07 \pm 0.07$ & $2.13 \pm 0.10$ \\
\hline
\end{tabular}

Values are expressed as mean $\pm \operatorname{SE}(n=5)$

$N S$ not significantly different among groups

\section{Oral toxicity study of $P$. acidilactici $\mathrm{J} 9$ in a mice model:}

\section{histopathology observations}

For the histopathology test of $P$. acidilactici J9administrated mice, liver and kidney were stained by hematoxylin and eosin. We have chosen to observe liver and kidney because those two are representative organs that react to toxicity [27]. As the result of the histopathology test, no lesions were observed in the liver, like infection, necrosis, iron pigmentation, and bilirubin pigmentation. The structure of liver cells were also normal (Fig. 2a). There was no lesions in the kidney, like infection and necrosis, and no changes were observed in kidney cells (Fig. 2b). Therefore, there is no significant changes in liver and kidney, and no extraordinary pathologic abnormality dependent on dose of experimental materials were observed in both the control group and administration group as the result of the histopathology test. This opinion seems to correspond with the long-term change of weight as well as the blood biochemical change. Mijung Lee had validated the histopathology findings.

Inhibition of adhesion and growth of H.pylori in gastric epithelial cells in the presence of $P$. acidilactici J9

The adhesion and growth of $H$. pylori were inhibited by a $24 \mathrm{~h}$ treatment of $H$. pylori and $P$. acidilactici $\mathrm{J9}$ on AGS cells, which are gastric cancer cells. Compared to the control group (AGS cell and H.pylori), the number 
Table 7 Levels of serum biochemical indices of male and female (mice) treated orally with P. acidilactici J9 for 14 days

\begin{tabular}{|c|c|c|c|c|c|}
\hline \multirow[t]{2}{*}{ Sex } & \multirow[t]{2}{*}{ Parameters } & \multicolumn{4}{|l|}{ Dose (mg) } \\
\hline & & Control & 500 & 1000 & 2000 \\
\hline \multirow[t]{13}{*}{ Male } & Glu & $256.40 \pm 11.91$ & $243.00 \pm 42.57$ & $234.20 \pm 25.82$ & $230.80 \pm 31.32$ \\
\hline & BUN & $18.68 \pm 3.87$ & $21.54 \pm 5.78$ & $20.50 \pm 6.22$ & $18.24 \pm 2.60$ \\
\hline & Crea & $0.28 \pm 0.04$ & $0.29 \pm 0.02$ & $0.27 \pm 0.02$ & $0.27 \pm 0.03$ \\
\hline & T-Chol & $79.00 \pm 4.36$ & $85.20 \pm 4.92$ & $82.40 \pm 6.80$ & $81.80 \pm 4.66$ \\
\hline & TP & $4.74 \pm 0.05$ & $4.82 \pm 0.24$ & $4.76 \pm 0.11$ & $4.68 \pm 0.16$ \\
\hline & ALB & $1.70 \pm 0.07$ & $1.72 \pm 0.08$ & $1.68 \pm 0.04$ & $1.68 \pm 0.13$ \\
\hline & T-BIL & $0.06 \pm 0.05$ & $0.04 \pm 0.05$ & $0.08 \pm 0.04$ & $0.08 \pm 0.04$ \\
\hline & ALP & $133.00 \pm 19.51$ & $137.80 \pm 9.65$ & $126.20 \pm 19.82$ & $137.40 \pm 15.96$ \\
\hline & AST (GOT) & $56.20 \pm 15.07$ & $65.20 \pm 13.18$ & $48.00 \pm 7.35$ & $57.40 \pm 13.28$ \\
\hline & ALT (GPT) & $28.80 \pm 4.15$ & $28.00 \pm 4.18$ & $22.20 \pm 1.30$ & $25.20 \pm 4.49$ \\
\hline & $\mathrm{TG}$ & $66.40 \pm 26.88$ & $64.40 \pm 31.45$ & $49.80 \pm 23.85$ & $39.40 \pm 17.94$ \\
\hline & $\mathrm{A} / \mathrm{G}$ & $0.56 \pm 0.05$ & $0.56 \pm 0.05$ & $0.52 \pm 0.04$ & $0.56 \pm 0.05$ \\
\hline & $B / C$ & $66.61 \pm 12.59$ & $74.13 \pm 18.80$ & $76.83 \pm 22.46$ & $69.05 \pm 11.10$ \\
\hline \multirow[t]{13}{*}{ Female } & Glu & $214.40 \pm 37.40$ & $229.60 \pm 47.45$ & $228.40 \pm 40.32$ & $231.00 \pm 66.87$ \\
\hline & BUN & $25.16 \pm 5.42$ & $24.70 \pm 5.07$ & $23.06 \pm 3.26$ & $22.58 \pm 4.50$ \\
\hline & Crea & $0.27 \pm 0.05$ & $0.25 \pm 0.05$ & $0.28 \pm 0.03$ & $0.26 \pm 0.03$ \\
\hline & T-Chol & $76.80 \pm 8.11$ & $70.20 \pm 5.97$ & $78.80 \pm 13.44$ & $80.00 \pm 9.85$ \\
\hline & TP & $4.82 \pm 0.08$ & $4.72 \pm 0.16$ & $4.78 \pm 0.20$ & $4.70 \pm 0.23$ \\
\hline & ALB & $1.74 \pm 0.05$ & $1.74 \pm 0.05$ & $1.74 \pm 0.05$ & $1.72 \pm 0.04$ \\
\hline & T-BIL & $0.00 \pm 0.00$ & $0.02 \pm 0.04$ & $0.02 \pm 0.04$ & $0.02 \pm 0.04$ \\
\hline & ALP & $168.20 \pm 8.93$ & $173.40 \pm 10.31$ & $154.20 \pm 13.88$ & $153.60 \pm 26.37$ \\
\hline & AST (GOT) & $68.20 \pm 17.02$ & $67.60 \pm 14.57$ & $66.80 \pm 8.20$ & $78.40 \pm 18.01$ \\
\hline & ALT (GPT) & $21.00 \pm 12.88$ & $22.80 \pm 3.11$ & $24.60 \pm 3.51$ & $23.00 \pm 3.39$ \\
\hline & $\mathrm{TG}$ & $0.56 \pm 0.05$ & $43.00 \pm 9.70$ & $27.00 \pm 3.00$ & $34.20 \pm 15.45$ \\
\hline & $A / G$ & $0.56 \pm 0.05$ & $0.58 \pm 0.04$ & $0.56 \pm 0.05$ & $0.58 \pm 0.04$ \\
\hline & $\mathrm{B} / \mathrm{C}$ & $94.97 \pm 12.02$ & $103.82 \pm 32.56$ & $82.32 \pm 13.29$ & $87.08 \pm 24.74$ \\
\hline
\end{tabular}

Values are expressed as mean \pm SE $(n=5)$

NS not significantly different among groups

of $H$. pylori analyzed by FACS significantly $(p<0.01)$ decreased after incubation of AGS cell with $P$. acidilactici J9 for $24 \mathrm{~h}$. Control biological triplicate groups are also analyzed for statistical options (Fig. 3 and Figure S1 in Additional file 1).

\section{Discussion}

P. acidilactici $\mathrm{J} 9$ exerts as an antagonism against other enteric pathogens, primarily through the production of lactic acid and secretion of bacteriocin [28-34]. Thermo-stable bacteriocin is an antimicrobial peptide known to have a strong activity against food bacteria and pathogenic enteric bacteria [28, 35-38]. For these reasons, bacteriocin secreted by $P$. acidilactici 19 has a potential to inhibit other pathogenic bacteria, and probiotics including $P$. acidilactici $\mathrm{J} 9$ have potential to be used for commercial healthcare products like beverages and foods [21]. However, a systematic study on its repeated oral administration toxicity has not been reported yet.

Various antibiotics have been used for H.pylori eradication [39-42], since it is known to be an important causative agent of peptic ulcer, gastritis, gastric cancer, or mucosa associated lymphoid tissue lymphoma [43]. These antimicrobial agents have been pointed out for various problems such as adverse effects, risk of reinfection due to increased $\mathrm{pH}$, appearance of resistant bacteria, and high cost [42, 44-47]. Recently, there is growing interest in probiotic lactic acid bacteria, which can play a role in the treatment of H.pylori by directly acting on H.pylori, with minimal clinical side effects of antibiotics [48-52].

This study investigated the toxicity and anti-H.pylori effect of $P$. acidilactici J9. Daily administration of $P$. acidilactici $\mathrm{J} 9$ in mice for 2 week showed no abnormal clinical signs in body weight, hematology, food intake 
a

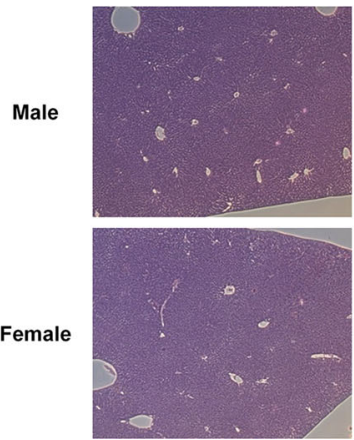

Control
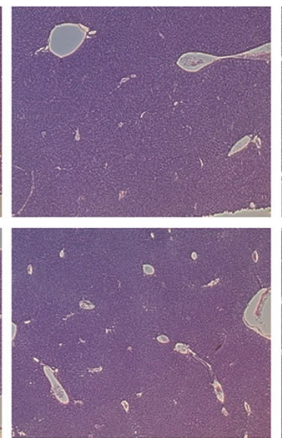

$500 \mathrm{mg} / \mathrm{kg}$

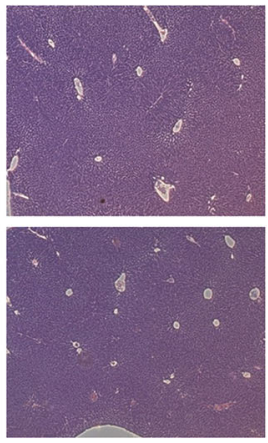

$1,000 \mathrm{mg} / \mathrm{kg}$
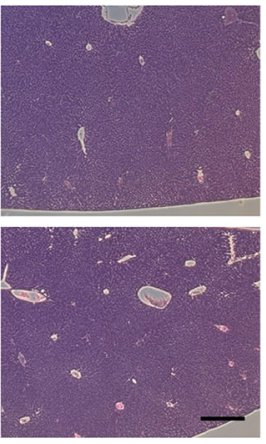

$2,000 \mathrm{mg} / \mathrm{kg}$

b
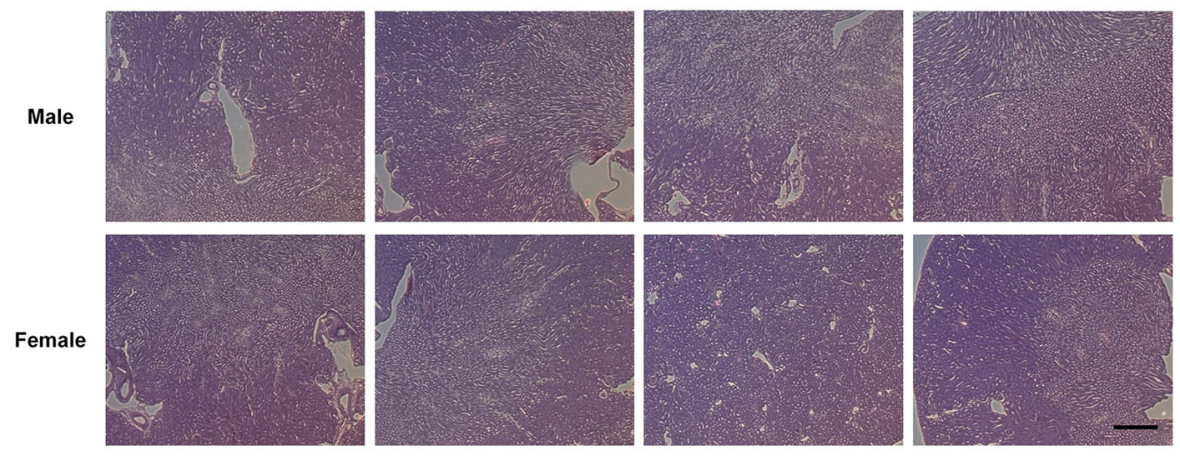

Control

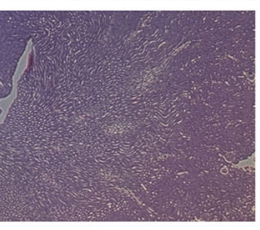

$500 \mathrm{mg} / \mathrm{kg}$

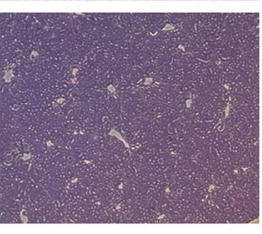

$1,000 \mathrm{mg} / \mathrm{kg}$

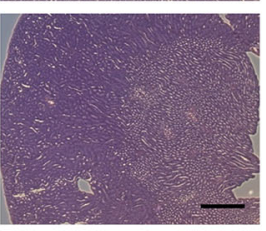

$2000 \mathrm{mg} / \mathrm{kg}$

Fig. 2 Histopathological examinations of the liver and Kidney. a, b Female and male C57BL / 6 mice were orally administered with P. acidilactici $J 9$ for 14 days. The liver and kidneys of the control and P. acidilactici $\mathrm{J} 9$ administration animals were extracted and fixed with $10 \%$ neutral buffered formalin solution on the final necropsy day of all animals after gross lesion observation. Pathological lesions and structures such as liver, kidney infection, necrosis, and iron and bilirubin pigmentation were confirmed by $\mathrm{H} \& \mathrm{E}$ staining. Bar $=30 \mu \mathrm{m}, \mathrm{N}=10$ samples per group
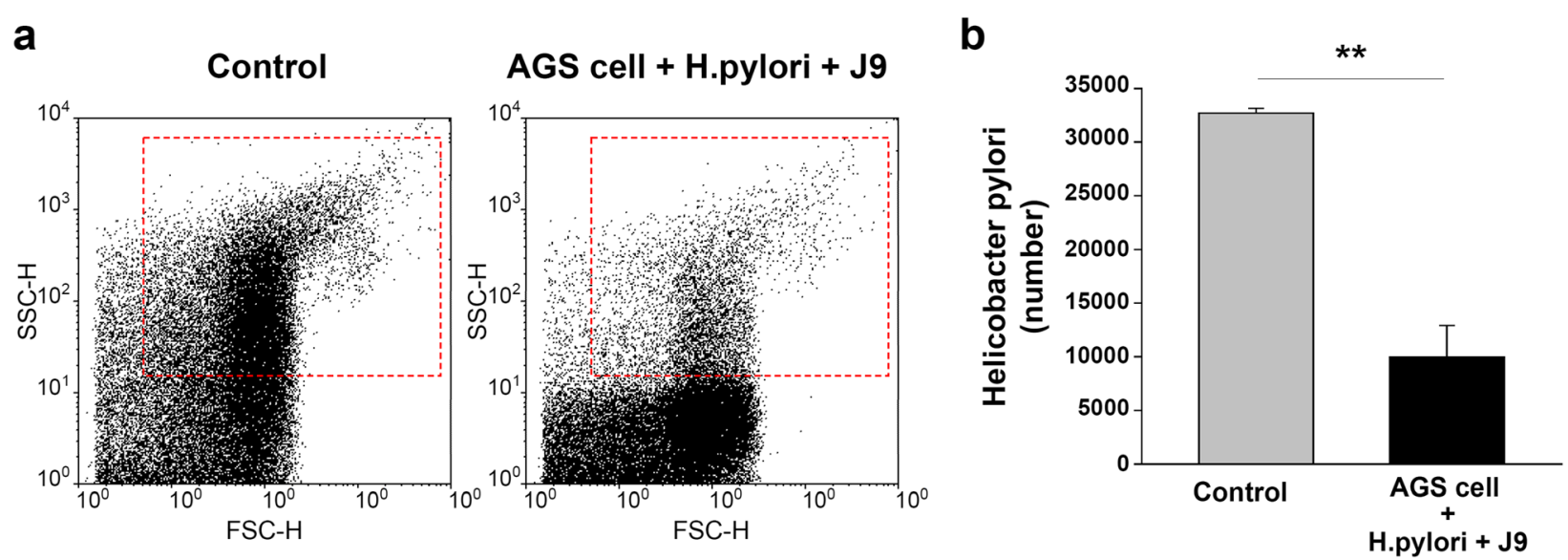

Fig. 3 P. acidilactici $\mathrm{J} 9$ inhibits adhesion and growth of $H$. pylori in gastric epithelial cells. a After $H$. pylori supernatant and P. acidilactici J9 were treated for $24 \mathrm{~h}$ in AGS cells, H. pylori count was confirmed by flow cytometry. In the control group, the H.pylori number was confirmed by flow measurement after $24 \mathrm{~h}$ of treatment with H.pylori in the AGS cell. $\mathbf{b} \mathrm{H}$. pylori number was quantified by a flow cytometer. The experiment was repeated three times and the data are shown as the mean (SEM). ${ }^{* *} p<0.01$ versus control group 
and water consumption. In all test groups, no general symptoms and deaths from the test substance were observed. During the entire test period, body weight continuously increased but no significant change was observed with the control group. In addition, there were no significant differences in the gross observation, longterm weight change, hematology, blood biochemical and histopathologic examination of the organ in all the test substance administration groups, and all of them were within the normal range. As a result of repeated toxicity test for 2 weeks, $P$. acidilactici J9 was judged to be a safe and low-toxic substance. But further investigation will be needed to interpret the data that female mice at 1000 $\mathrm{mg}$ of dose showed higher heart, kidney $(\mathrm{L}, \mathrm{R})$ weight and lower thymus weight when compared to control, and that female mice at 500 and $2000 \mathrm{mg}$ of dose showed lower kidney (L) weight when compared to control.

P. acidilactici $\mathrm{J9}$, inhibits the adhesion of H.pylori to AGS gastric cancer cells. Probiotics refers to living microorganisms that are beneficial to the human body when consumed in moderate quantities [53, 54]. Most probiotics known to date are lactic acid bacteria [55, 56]. Probiotic bacteria such as lactic acid bacteria and beneficial bacteria survive in the stomach acid and bile acid in the body, reach the small intestine, multiply in the intestines and settle [57, 58]. It has a beneficial effect on health in the colon, and these probiotics should be nontoxic and non-pathogenic $[59,60]$. Ingestion of probiotics not only helps maintain health, it also helps to improve various diseases such as infants, irritable bowel syndrome, and inflammatory bowel disease [61].

Based on our in vivo and in vitro results, when used as probiotics, $P$. acidilactici $\mathrm{J} 9$ may help decrease the occurrence of gastritis and reduce the risk of H.pylori infection with promising safety issues, without side effects.

\section{Conclusions}

In conclusion, we reported the toxicity and anti-H.pylori effect of $P$. acidilactici 19 . Daily administration of $P$. acidilactici $\mathrm{J} 9$ in mice for 2 week showed no abnormal clinical signs in body weight, hematology, food intake and water consumption. Also, P. acidilactici J9, inhibited the adhesion of H.pylori to AGS gastric cancer cells. Based on our in vivo and in vitro results, when used as probiotics, $P$. acidilactici $\mathrm{J} 9$ might have the potential to decrease the occurrence of gastritis and the risk of H.pylori infection with promising safety issues, without side effects.

\section{Methods}

\section{Model organisms and conditions}

C57BL/6 mice of 4 weeks of age without certain pathogens are purchased from Orient Bio (Seongnam, Korea) at an amount of 20 males and females each. Normal and healthy mice without any weight loss are used in experiment by clinical observation during 7 days of education. Feeds are the following; solid feeds for laboratory animal are freely offered, and drinking water. The filtrationpurified water is also freely offered to mice. The mice were house in groups with ad libitum access to food and water and a $12 \mathrm{~h} \mathrm{light} \mathrm{/} 12 \mathrm{~h}$ dark cycle. Also, P. acidilactici $\mathrm{J} 9$ has been prepared through Industry Promotion Administration.

\section{Configuration of test group and set of dosage setting}

Dosage was set by MFDS (Ministry of Food and Drug Safety) standards. Maximum dosage is set to $2000 \mathrm{mg} /$ $\mathrm{kg} /$ day for both male and female, with the geometric ratio of $1 / 2$, low dose group, medium dose group, and high dose group are set at 500, 1000, and $2000 \mathrm{mg}$ per body weight $(\mathrm{kg})$ respectively. 500,1000, $2000 \mathrm{mg}$ of dosage corresponds to $5 \times 10^{8} \mathrm{CFU}, 1 \times 10^{9} \mathrm{CFU}$, and $2 \times 10^{9}$ CFU, however, we used the $\mathrm{mg} / \mathrm{ml}$ unit which is more commonly used in the animal experiments. The number of mice in each group are set to 5 males and females each. Dosage is set to not exceed $0.2 \mathrm{ml}$ per $10 \mathrm{~g}$ and calculated according to the body weight measured just before administration. Test materials are well-mixed to sterile distilled water before administration, and they are directly injected into the stomach by sonde for oral administration for once a day during 2 weeks. Sterile distilled water for injection is used as reference material.

\section{Normal symptoms and observation of lethality in mice}

Observation is conducted for $6 \mathrm{~h}$ after oral administration and starting from the next day, to observe change of general condition, as well as expression of addiction. This was held in presence of dead mice and symptoms that can be expressed by the test materials are observed carefully. In the case of abnormality, the type and the extent of symptoms are recorded individually. All mice were checked for death or critical condition.

\section{Measurement of weight, feed and water intake}

For every animal, change of weight is measured just before the administration of test materials once a week at a certain time during 2 weeks. Intake of feeds and water is measured and calculated weekly.

\section{Necropsy and naked eye examination}

Mice were anesthetized by $\mathrm{CO}_{2}$; the air atmosphere of chamber that contains mice was replaced to $\mathrm{CO}_{2}$ with the volume displacement rate of $20 \% / \mathrm{min}$, and all surgical procedures were performed under general anesthesia. Euthanasia of mice was done by collecting $0.5 \mathrm{ml}-0.8$ $\mathrm{ml}$ of blood from the heart under anesthesia. The protocols were in accordance with official governmental 
guidelines, and all efforts were made to minimize the number of mice used and their suffering. Also, other organs was obtained by mice. The brain, kidney, liver, lung, reproductive organ, heart, spleen, and thymus are extracted and weighed. External findings such as abnormality of subcutaneous, internal organs and brain were observed with the naked eye.

\section{Blood biochemical}

The hematologic analysis of the serum is performed the same day of the necropsy, which is collected from a $3000 \mathrm{rpm}, 20 \mathrm{~min}$ long, centrifugation of the blood and conducted by auto-analyzer (Hitachi-747, Hitachi Medical Co., Tokyo, Japan). Glucose; GLU, Blood Urea Nitrogen; BUN, Creatinine; CREA, Total cholesterol; TCHOL, Albumin; ALB, Total Bilirubin; T-BIL, Alkaline Phosphatase; ALP, Aspartate Aminotransferase; AST (GOT), Alanine Aminotransferase; ALT (GPT), Triglyceride; TG, and Total protein; TP are measured.

\section{Hematology}

Mice were fasted for $8 \mathrm{~h}$ followed by the anesthetization before the necropsy. Part of the blood from the exsanguination is EDTA-treated and stored in tubes and then analyzed by blood auto-analyzer (System SE-9000, TOAMedical Electronics Co., Ltd., Kobe, Japan). Red blood cells, $\mathrm{RBC}$, hematocrit, $\mathrm{HCT}$, hemoglobin, $\mathrm{Hb}$, mean corpuscular volume, $\mathrm{MCV}$, mean corpuscular hemoglobin, $\mathrm{MCH}$, mean corpuscular hemoglobin concentration, $\mathrm{MCHC}$, white blood cells, WBC, Hemoglobin, HGB, Cellular Hb Concentration Mean, CHCM, Red Cell Distribution Width, RDW, $\mathrm{Hb}$ Distribution Width, HDW, Cellular Hb content, $\mathrm{CH}$, Cellular Hb Distribution Width, CHDW, Platelet, PLT, Platelet Distribution Width, PDW, Plateletcrit, PCT, Neutrophil, NEUT, Neutrophil, NEUT\%, Lymphocyte, LYMP H, Lymphocyte \%, LYMPH\%, Monocyte, MONO, Monocyte \%, MONO\%, Eosinophil, EOS, Eosinophil \%, EOS\%, Basophil, BASO, Basophil \%, BASO\%, Large Unstained Cells, LUC, Large Unstained Cells, LUC\%, Reticulocyte Count, Retic\#, Reticulocyte \%, Retic\%, Mean Corpuscular Volume of Retics, MCVr, Mean Corpuscular Volume of Retics \%, MCVr\%, Red Cell Distribution Width of Retics, RDWr*, Hb Distribution Width of Retics, HDWr*, Cellular $\mathrm{Hb}$ of Retics, $\mathrm{CHr}$, and Cellular $\mathrm{Hb}$ Distribution Width of Retics, CHDWr* are measured.

\section{Histopathology}

Liver and kidney were extracted and fixed with a $10 \%$ neutral buffered formalin solution the day of final necropsy, after the observation of gross lesions on every animal which were administered with test materials. Then paraffin embedding wass conducted and hematoxylin \& eosin dye performed with the sections of $3 \sim 4$ um sections. Mijung Lee had validated the findings.

\section{H. pylori preparation}

H. pylori (ATCC 43504) used in this study were obtained and inoculated onto chocolate media, incubated for $5 \sim 7$ days at $37^{\circ} \mathrm{C}$ in a $10 \% \mathrm{CO}_{2}$ incubator under aerobic conditions and then used for the examination. When the chocolate media is filled over $90 \%, H$. pylori is swabbed with sterilized swabs and suspended in $20 \mathrm{ml}$ of RPMI-1640 media to form the H. pylori suspension.

\section{Cell culture}

The human gastric adenocarcinoma cell lines AGS (KCLB 21739; Korea) cells were seeded at a density of $1 \times 10^{5}$ cells in $2 \mathrm{ml}$ of RPMI-1640 (RPMI-1640; Gibco, Carlsbad, CA, USA) supplemented with 10\% fetal bovine serum (FBS; Gibco, Carlsbad, CA, USA) and 1\% penicillin-streptomycin (Invitrogen, USA) into 6 well culture plates (SPL) and cultured for $2 \sim 3$ days at $37^{\circ} \mathrm{C}$ in a $5 \% \mathrm{CO}_{2}$ incubator.

\section{Adhesion assay}

When the AGS cell reach a density of $80 \%$ of the seeding plate, we eliminate the media from the plate and wash with phosphate buffered saline (PBS: Welgene, Daegu, Korea) 3 times. Experimental groups are as follows. For negative control, only AGS is seeded. For positive control, AGS is treated by $1 \mathrm{ml}$ of $H$. pylori suspension. For the measurement of suppression of attachment, AGS is treated by $1 \mathrm{ml}$ of $H$. pylori suspension $\left(1 \times 10^{8} \mathrm{CFU} / \mathrm{ml}\right)$ and $P$. acidilactici $\mathrm{J} 9\left(1 \times 10^{8} \mathrm{CFU} / \mathrm{ml}\right)$ at a multiplicity of infection of 100. The culture plates seeded with AGS treated by $H$. pylori and P. acidilactici $\mathrm{J} 9$ are incubated for $90 \mathrm{~min}$ at $37{ }^{\circ} \mathrm{C}$ in a $5 \% \mathrm{CO}_{2}$ incubator. The culture media is eliminated and the cells are carefully harvested. The cells are suspended in 500ul of PBS then examined with FACS.

\section{Flow cytometry}

The culture media is eliminated and the cells were washed and carefully harvested in PBS (phosphate buffered saline, WelGene, Daegu, Korea) using a cell scraper. Cells were counted and $1 \times 10^{6}$ cells were suspended in $1 \mathrm{ml}$ cold PBS. Cells $\left(5 \times 10^{6}\right.$ or $\left.1 \times 10^{7}\right)$ were centrifuged at $1200 \mathrm{rpm}$ for $5 \mathrm{~min}$. The cells are suspended in 500ul of PBS then flow cytometric analysis was performed (FACS Calibur, BD Bioscience, CA, USA). The data were analyzed using Flowing Software (www.flowingsoftware. com).

\section{Statistical analysis}

All values shown in the figures are presented as mean \pm standard error. A 2-tailed probability value below 0.05 was considered statistically significant. Data were analyzed using SPSS version 17.0 (SPSS Inc., USA). 


\section{Supplementary Information}

The online version contains supplementary material available at https://doi. org/10.1186/s12866-020-02055-4

Additional file 1. Populations of H.pylori were analyzed with a flow cytometer. When the chocolate media was filled with over $90 \%$, Helicobacter pylori was swabbed with sterilized swabs and suspended in RPMl-1640 media $20 \mathrm{ml}$ to form Helicobacter pylori suspension. The population in a red gate were assayed as Helicobacter pylori.

Additional file $\mathbf{2}$.

\section{Abbreviations}

P. acidilactici: Pediococcus acidilactici; H. pylori: Helicobacter pylori;

AGS: Adenocarcinoma gastric; LAB: Lactic acid bacteria; RBC: Red blood cells; HCT: Hematocrit; Hb: Hemoglobin; MCV: Mean corpuscular volume; $\mathrm{MCH}$ : Mean corpuscular hemoglobin; MCHC: Mean corpuscular hemoglobin concentration; WBC: White blood cells; HGB: Hemoglobin; CHCM: Cellular Hb Concentration Mean; RDW: Red Cell Distribution Width; HDW: Hb Distribution Width; $\mathrm{CH}$ : Cellular Hb content; CHDW: Cellular Hb Distribution Width; PLT: Platelet; PDW: Platelet Distribution Width; PCT: Plateletcrit; NEUT: Neutrophil; NEUT\%: Neutrophil \%; LYMPH: Lymphocyte; LYMP H\%: Lymphocyte \%; MONO: Monocyte; MONO\%: Monocyte \%; EOS: Eosinophil; EOS\%: Eosinophil \%; BASO: Basophil; BASO\%: Basophil \%; LUC: Large Unstained Cells; LUC\%: Large Unstained Cells; Retic\#: Reticulocyte Count; Retic\%: Reticulocyte \%; MCVr: Mean Corpuscular Volume of Retics; MCVr\%: Mean Corpuscular Volume of Retics \%; RDWr*: Red Cell Distribution Width of Retics; HDWr*: Hb Distribution Width of Retics; CHr: Cellular Hb of Retics; CHDWr*: Cellular Hb Distribution Width of Retics; GLU: Glucose; BUN: Blood Urea Nitrogen; CREA: Creatinine; T-CHOL: Total cholesterol; ALB: Albumin; T-BIL: Total Bilirubin; ALP: Alkaline Phosphatase; AST (GOT): Aspartate Aminotransferase; ALT (GPT): Alanine Aminotransferase; TG: Triglyceride; TP: Total protein; FACS: Fluorescence-activated cell sorting

\section{Acknowledgements}

The authors gratefully acknowledge Financial assistance from the 0720142100 University Industrial Technology Force. We also express our appreciation to professor Nayoung Kim from Seoul National University Bundang Hospital for kindly providing H.pylori stock and the human gastric adenocarcinoma cell lines AGS (KCLB 21739; Korea) cells. We are also thankful to PDXen Biosystems Co. for offering technical assistant and idea.

\section{Authors' contributions}

ML performed experiments, analyzed data, wrote paper, JC provided advice in study design, critically discussed results, co-edited paper, KYK provided ad vice in study design, critically discussed results, co-edited paper, WI provided advice in study design, critically discussed results, co-edited paper, MK provided advice in study design, critically discussed results, co-edited paper. All authors have read and approved the manuscript

\section{Funding}

This work was supported from the 0720142100 University Industrial Technology Force, and by 2018 research fund from 'The Korean Society of Ginseng'. The source of funding had no role in the study design, data collection, analysis, interpretation or writing of the manuscript.

\section{Availability of data and materials}

Data generated by and used in the study is available from the corresponding author upon reasonable request.

\section{Ethics approval and consent to participate}

All experimental animal procedures performed were approved by the Institutional Animal Care and Use Committee (IACUC, Approval number: 160043-C2A1) of Seoul National University Hospital, which was accredited by the Association for the Assessment and Accreditation of Laboratory Animal Care International.

\section{Consent for publication}

Not applicable.

\section{Competing interests}

The authors declare that they have no competing interests.

\section{Author details}

${ }^{1}$ Department of Neurology, Biomedical Research Institute, Seoul National University Hospital, 101 Daehak-ro, Jongno-gu, Seoul 03080, South Korea. ${ }^{2}$ Department of Veterinary Internal Medicine and Geriatrics, College of Veterinary Medicine, Kangwon National University, Gangwon-do, South Korea. ${ }^{3}$ Department of Psychology, Fordham University, New York, NY, USA. ${ }^{4}$ Neuroscience Research Institute, Seoul National University College of Medicine, Seoul, South Korea. ${ }^{5}$ Protein Metabolism Medical Research Center, College of Medicine, Seoul National University Hospital, Seoul, South Korea.

Received: 19 September 2020 Accepted: 26 November 2020

Published online: 09 December 2020

\section{References}

1. Cross ML, Ganner A, Teilab D, Fray LM. Patterns of cytokine induction by gram-positive and gram-negative probiotic bacteria. FEMS Immunol Med Microbiol. 2004;42(2):173-80. https://doi.org/10.1016/j.femsim.2004.04.001.

2. Jack RW, Tagg JR, Ray B. Bacteriocins of gram-positive bacteria. Microbiol Rev. 1995;59(2):171-200.

3. De Vuyst L, Leroy F. Bacteriocins from lactic acid bacteria: production, purification, and food applications. J Mol Microbiol Biotechnol. 2007;13(4): 194-9. https://doi.org/10.1159/000104752.

4. Josson K, Scheirlinck T, Michiels F, Platteeuw C, Stanssens P, Joos H, et al. Characterization of a gram-positive broad-host-range plasmid isolated from Lactobacillus hilgardii. Plasmid. 1989;21(1):9-20.

5. Marshall BJ. Helicobacter pylori. Am J Gastroenterol. 1994;89(8 Suppl): S116-28.

6. Lind T, Megraud F, Unge P, Bayerdorffer E, O'Morain C, Spiller R, et al. The $\mathrm{MACH} 2$ study: role of omeprazole in eradication of helicobacter pylori with 1-week triple therapies. Gastroenterology. 1999;116(2):248-53.

7. Maeda S, Yoshida H, Matsunaga H, Ogura K, Kawamata O, Shiratori Y, et al. Detection of clarithromycin-resistant helicobacter pylori strains by a preferential homoduplex formation assay. J Clin Microbiol. 2000;38(1):210-4.

8. Maeda S, Yoshida H, Ogura K, Kanai F, Shiratori Y, Omata M. Helicobacter pylori specific nested PCR assay for the detection of $23 \mathrm{~S}$ rRNA mutation associated with clarithromycin resistance. Gut. 1998:43(3):317-21.

9. Aiba Y, Suzuki N, Kabir AM, Takagi A, Koga Y. Lactic acid-mediated suppression of helicobacter pylori by the oral administration of Lactobacillus salivarius as a probiotic in a gnotobiotic murine model. Am J Gastroenterol. 1998;93(11):2097-101. https://doi.org/10.1111/j.1572-0241. 1998.00600.x

10. lerardi E, Giorgio F, Losurdo G, Di Leo A, Principi M. How antibiotic resistances could change helicobacter pylori treatment: a matter of geography? World J Gastroenterol. 2013;19(45):8168-80. https://doi.org/10. 3748/wjg.v19.i45.8168.

11. Sachdeva A, Nagpal J. Effect of fermented milk-based probiotic preparations on helicobacter pylori eradication: a systematic review and meta-analysis of randomized-controlled trials. Eur J Gastroenterol Hepatol. 2009;21(1):45-53. https://doi.org/10.1097/MEG.0b013e32830d0eff.

12. Hsieh PS, Tsai YC, Chen YC, Teh SF, Ou CM, King VA. Eradication of helicobacter pylori infection by the probiotic strains Lactobacillus johnsonii MH-68 and L. salivarius ssp. salicinius AP-32. Helicobacter. 2012;17(6):466-77. https://doi.org/10.1111/j.1523-5378.2012.00992.x.

13. Johnson-Henry KC, Nadjafi M, Avitzur Y, Mitchell DJ, Ngan BY, Galindo-Mata $E$, et al. Amelioration of the effects of Citrobacter rodentium infection in mice by pretreatment with probiotics. J Infect Dis. 2005;191(12):2106-17. https://doi.org/10.1086/430318.

14. Tien MT, Girardin SE, Regnault B, Le Bourhis L, Dillies MA, Coppee JY, et al. Anti-inflammatory effect of Lactobacillus casei on Shigella-infected human intestinal epithelial cells. J Immunol. 2006;176(2):1228-37.

15. Fernandez MF, Boris S, Barbes C. Probiotic properties of human lactobacilli strains to be used in the gastrointestinal tract. J Appl Microbiol. 2003;94(3): 449-55

16. Lionetti E, Indrio F, Pavone L, Borrelli G, Cavallo L, Francavilla R. Role of probiotics in pediatric patients with helicobacter pylori infection: a comprehensive review of the literature. Helicobacter. 2010;15(2):79-87. https://doi.org/10.1111/j.1523-5378.2009.00743.x. 
17. De Keersmaecker SC, Verhoeven TL, Desair J, Marchal K, Vanderleyden J, Nagy I. Strong antimicrobial activity of Lactobacillus rhamnosus GG against Salmonella typhimurium is due to accumulation of lactic acid. FEMS Microbiol Lett. 2006; 259(1):89-96. https://doi.org/10.1111/j.1574-6968.2006.00250.x.

18. Sartor RB. Probiotic therapy of intestinal inflammation and infections. Curr Opin Gastroenterol. 2005;21(1):44-50.

19. Mack DR, Michail S, Wei S, McDougall L, Hollingsworth MA. Probiotics inhibit enteropathogenic E. coli adherence in vitro by inducing intestinal mucin gene expression. Am J Phys. 1999;276(4 Pt 1):G941-50.

20. Coconnier MH, Lievin V, Hemery E, Servin AL. Antagonistic activity against helicobacter infection in vitro and in vivo by the human Lactobacillus acidophilus strain LB. Appl Environ Microbiol. 1998;64(11):4573-80.

21. Hong S-J, Chong M-S, Ahn S-H. A review on effects of probiotics in atopic dermatitis. J Korean Med Ophthalmol Otolaryngol Dermatol. 2020;33(1):2544. https://doi.org/10.6114/jkood.2020.33.1.025.

22. Bhunia AK, Johnson MC, Ray B. Purification, characterization and antimicrobial spectrum of a bacteriocin produced by Pediococcus acidilactici. J Appl Bacteriol. 1988;65(4):261-8. https://doi.org/10.1111/j.13652672.1988.tb01893.x

23. Ribeiro MCO, Vandenberghe LPS, Spier MR, Paludo KS, Soccol CR, Soccol VT. Evaluation of probiotic properties of Pediococcus acidilactici B14 in association with Lactobacillus acidophilus ATCC 4356 for application in a soy based aerated symbiotic dessert. Braz Arch Biol Technol. 2014;57:755-65.

24. Barbosa J, Borges S, Teixeira P. Pediococcus acidilactici as a potential probiotic to be used in food industry. Int J Food Sci Technol. 2015;50(5): 1151-7. https://doi.org/10.1111/ijfs.12768.

25. McNicholl AG, Molina-Infante J, Lucendo AJ, Calleja JL, Pérez-Aisa Á, Modolell I, et al. Probiotic supplementation with Lactobacillus plantarum and Pediococcus acidilactici for Helicobacter pylori therapy: a randomized, double-blind, placebo-controlled trial. Helicobacter. 2018;23(5):e12529. https://doi.org/10.1111/hel.12529.

26. Zuo F, Appaswamy A, Gebremariam HG, Jonsson AB. Role of Sortase A in lactobacillus gasseri Kx110A1 adhesion to gastric epithelial cells and competitive exclusion of helicobacter pylori. Front Microbiol. 2019;10:2770. https://doi.org/10.3389/fmicb.2019.02770.

27. Belhattab R, Merouani N. Acute toxicity of Aristolochia longa L. of aqueous extract in mice. J Drug Deliv Ther. 2020;10(3):4-10. https://doi.org/10.22270/ jddt.v10i3.4055.

28. Anastasiadou S, Papagianni M, Filiousis G, Ambrosiadis I, Koidis P. Pediocin SA-1, an antimicrobial peptide from Pediococcus acidilactici NRRL B5627: Production conditions, purification and characterization. Bioresour Technol. 2008:99(13):5384-90. https://doi.org/10.1016/j.biortech.2007.11.015.

29. Stonsaovapak S, Kaneko J, Izaki K. Characterization of Bacteriocin Produced by Pediococcus acidilactici Isolated from Fermented Pork in Thailand. Agric Nat Resour. 1994;28(2):310-3.

30. Bhunia AK, Johnson MC, Ray B, Kalchayanand N. Mode of action of pediocin AcH from Pediococcus acidilactici $\mathrm{H}$ on sensitive bacterial strains. J Appl Bacteriol. 1991;70(1):25-33. https://doi.org/10.1111/j.1365-2672.1991.tb03782.x.

31. Biswas SR, Ray P, Johnson MC, Ray B. Influence of growth conditions on the production of a Bacteriocin, Pediocin $\mathrm{AcH}$, by Pediococcus acidilactici $\mathrm{H}$. Appl Environ Microbiol. 1991;57(4):1265-7.

32. Bukhtiyarova M, Yang R, Ray B. Analysis of the pediocin AcH gene cluster from plasmid pSMB74 and its expression in a pediocinnegative Pediococcus acidilactici strain. Appl Environ Microbiol. 1994; 60(9):3405.

33. Bauer $\mathrm{R}$, Chikindas ML, Dicks LMT. Purification, partial amino acid sequence and mode of action of pediocin PD-1, a bacteriocin produced by Pediococcus damnosus NCFB 1832. Int J Food Microbiol. 2005;101(1):17-27. https://doi.org/10.1016/j.ijfoodmicro.2004.10.040.

34. Mehta R, Arya R, Goyal K, Singh M, K. Sharma A. Bio-preservative and therapeutic potential of Pediocin: recent trends and future perspectives. Recent Pat Biotechnol. 2013;7(3):172-8.

35. Mehta R, Arya R, Goyal K, Singh M, Sharma AK. Bio-preservative and therapeutic potential of pediocin: recent trends and future perspectives. Recent Pat Biotechnol. 2013;7(3):172-8.

36. Green G, Dicks LMT, Bruggeman G, Vandamme EJ, Chikindas ML. Pediocin PD-1, a bactericidal antimicrobial peptide from Pediococcus damnosus NCFB 1832. J Appl Microbiol. 1997;83(1):127-32. https://doi.org/10.1046/j. 1365-2672.1997.00241.x.

37. Oppegård C, Fimland G, Anonsen JH, Nissen-Meyer J. The Pediocin PA-1 accessory protein ensures correct disulfide bond formation in the antimicrobial peptide Pediocin PA-1. Biochemistry. 2015;54(19):2967-74. https://doi.org/10.1021/acs.biochem.5b00164.

38. Johnsen L, Fimland G, Eijsink V, Nissen-Meyer J. Engineering increased stability in the antimicrobial peptide Pediocin PA-1. Appl Environ Microbiol. 2000;66(11):4798-802. https://doi.org/10.1128/aem.66.11.4798-4802.2000.

39. Chiba N, Rao BV, Rademaker JW, Hunt RH. Meta-analysis of the efficacy of antibiotic therapy in eradicating helicobacter pylori. Am J Gastroenterol. 1992;87(12):1716-27.

40. Mégraud F. H. pylori antibiotic resistance: prevalence, importance, and advances in testing. Gut. 2004;53(9):1374-84. https://doi.org/10.1136/gut. 2003.022111.

41. De Francesco V, Giorgio F, Hassan C, Manes G, Vannella L, Panella C, et al. Worldwide H. pylori antibiotic resistance: a systematic review. J Gastrointestin Liver Dis. 2010;19(4):409-14.

42. Alba C, Blanco A, Alarcón T. Antibiotic resistance in helicobacter pylori. Curr Opin Infect Dis. 2017;30(5):489-97. https://doi.org/10.1097/QCO 0000000000000396

43. Sipponen $\mathrm{P}$, Hyvarinen $\mathrm{H}$. Role of helicobacter pylori in the pathogenesis of gastritis, peptic ulcer and gastric cancer. Scand J Gastroenterol Suppl. 1993; 196:3-6.

44. Andersson DI, Hughes D. Antibiotic resistance and its cost: is it possible to reverse resistance? Nat Rev Microbiol. 2010;8(4):260-71. https://doi.org/10. 1038/nrmicro2319.

45. Zullo A, De Francesco V, Bellesia A, Vassallo R, D'Angelo A, Scaccianoce G, et al. Bismuth-based quadruple therapy following $H$. pylori eradication failures: a multicenter study in clinical practice. J Gastrointestin Liver Dis. 2017;26(3):225-9. https://doi.org/10.15403/jgld.2014.1121.263.zul.

46. Li H, Liang X, Chen Q, Zhang W, Lu H. Inappropriate treatment in helicobacter pylori eradication failure: a retrospective study. Scand J Gastroenterol. 2018;53(2):130-3. https://doi.org/10.1080/00365521.2017. 1413132.

47. Mohammadi M, Attaran B, Malekzadeh R, Graham DY. Furazolidone, an underutilized drug for $H$. pylori eradication: lessons from Iran. Dig Dis Sci. 2017:62(8):1890-6. https://doi.org/10.1007/s10620-017-4628-5.

48. Kong $Y H$, Zhang $L$, Yang $Z Y$, Han $C$, Hu LH, Jiang HL, et al. Natural product juglone targets three key enzymes from helicobacter pylori: inhibition assay with crystal structure characterization. Acta Pharmacol Sin. 2008;29(7):870-6. https://doi.org/10.1111/j.1745-7254.2008.00808.x

49. Wu L, Wang Z, Sun G, Peng L, Lu Z, Yan B, et al. Effects of anti-H. pylori triple therapy and a probiotic complex on intestinal microbiota in duodenal ulcer. Sci Rep. 2019;9(1):12874. https://doi.org/10.1038/s41598-019-49415-3.

50. Kafshdooz T, Akbarzadeh A, Majdi Seghinsara A, Pourhassan M, Nasrabadi $H T$, Milani M. Role of probiotics in managing of helicobacter pylori infection: a review. Drug Res. 2017;67(2):88-93. https://doi.org/10.1055/s-0042-116441.

51. Goderska K, Agudo Pena S, Alarcon T. Helicobacter pylori treatment: antibiotics or probiotics. Appl Microbiol Biotechnol. 2018;102(1):1-7. https://doi.org/10.1007/s00253-017-8535-7.

52. Eslami M, Yousefi B, Kokhaei P, Jazayeri Moghadas A, Sadighi Moghadam B, Arabkari $V$, et al. Are probiotics useful for therapy of Helicobacter pylori diseases? Comp Immunol Microbiol Infect Dis. 2019;64:99-108. https://doi. org/10.1016/j.cimid.2019.02.010.

53. Preidis GA, Versalovic J. Targeting the human microbiome with antibiotics, probiotics, and prebiotics: gastroenterology enters the metagenomics era. Gastroenterology. 2009;136(6):2015-31.

54. Madsen K, Cornish A, Soper P, McKaigney C, Jijon H, Yachimec C, et al. Probiotic bacteria enhance murine and human intestinal epithelial barrier function. Gastroenterology. 2001;121(3):580-91.

55. Tannock GW. Probiotic properties of lactic-acid bacteria: plenty of scope for fundamental R \& D. Trends Biotechnol. 1997;15(7):270-4.

56. Dickerson FB, Stallings $C$, Origoni A, Katsafanas $E$, Savage $C L$, Schweinfurth LA, et al. Effect of probiotic supplementation on schizophrenia symptoms and association with gastrointestinal functioning: a randomized, placebo-controlled trial. Prim Care Companion CNS Disord. 2014;16(1):PCC.13m01579. https://doi.org/10. 4088/PCC.13m01579.

57. Cook MT, Tzortzis G, Charalampopoulos D, Khutoryanskiy W. Microencapsulation of probiotics for gastrointestinal delivery. J Control Release. 2012;162(1):56-67. https://doi.org/10.1016/j.jconrel.2012.06.003.

58. Yan F, Polk DB. Probiotic bacterium prevents cytokine-induced apoptosis in intestinal epithelial cells. J Biol Chem. 2002:277(52):50959-65. https://doi. org/10.1074/jbc.M207050200. 
59. Matsumoto M, Tsuji M, Sasaki H, Fujita K, Nomura R, Nakano K, et al.

Cariogenicity of the probiotic bacterium lactobacillus salivarius in rats. Caries Res. 2005;39(6):479-83. https://doi.org/10.1159/000088183.

60. Geier MS, Butler RN, Howarth GS. Probiotics, prebiotics and synbiotics: a role in chemoprevention for colorectal cancer? Cancer Biol Ther. 2006; 5(10):1265-9.

61. Floch MH. Probiotics, irritable bowel syndrome, and inflammatory bowel disease. Curr Treat Options Gastroenterol. 2003;6(4):283-8.

\section{Publisher's Note}

Springer Nature remains neutral with regard to jurisdictional claims in published maps and institutional affiliations.

Ready to submit your research? Choose BMC and benefit from:

- fast, convenient online submission

- thorough peer review by experienced researchers in your field

- rapid publication on acceptance

- support for research data, including large and complex data types

- gold Open Access which fosters wider collaboration and increased citations

- maximum visibility for your research: over $100 \mathrm{M}$ website views per year

At $\mathrm{BMC}$, research is always in progress.

Learn more biomedcentral.com/submissions 